\title{
Prevalence of congenital eye anomalies in a paediatric clinic in Ghana
}

A.A. Ilechie, ${ }^{\text {V. }}$.A. Essuman ${ }^{2}$ and S. Enyionam ${ }^{7}$

$$
\begin{aligned}
& \text { معدل انتشار العيوب الخلقية في العين في إحدى عيادات الأطفال في غانا }
\end{aligned}
$$

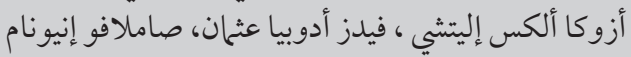

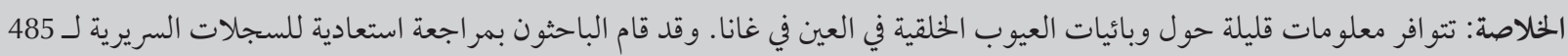

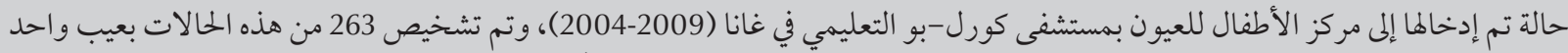

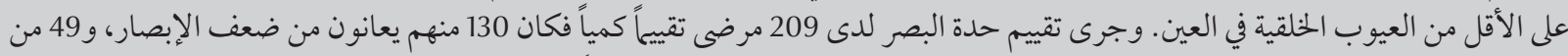

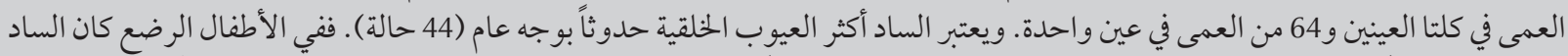

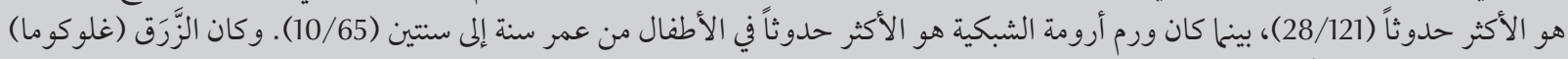

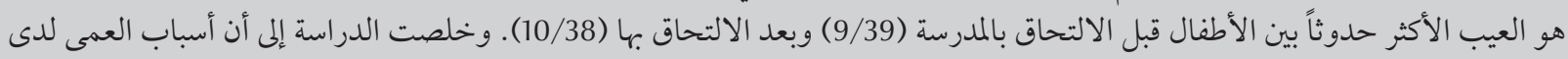

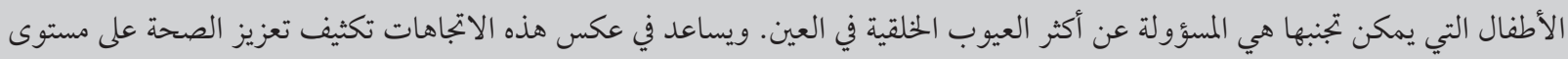

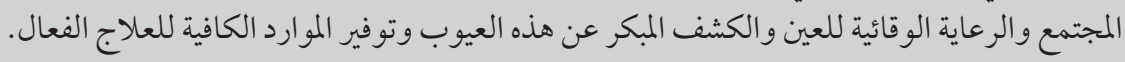

ABSTRACT There is little information about the epidemiology of congenital eye anomalies in Ghana. We retrospectively reviewed the clinical records of 485 admissions to the paediatric eye centre of the Korle-Bu Teaching Hospital, Ghana (2004-2009) and 263 were diagnosed with at least one anomaly. Visual acuity was quantitatively assessed in 209 patients and 130 had some visual impairment; 49 with bilateral and 64 with unilateral blindness. The most frequent congenital anomaly overall was cataract $(n=44)$. In infants, cataract was the most frequent finding (28/121). Toddlers most frequently presented with retinoblastoma (10/65). Glaucoma was the most frequent anomaly in preschool (9/39) and school (10/38) children. We conclude that avoidable causes of childhood blindness caused most congenital eye anomalies. Intensification of community-based health promotion and preventive eye care, early detection and provision of adequate resources for effective therapy could reverse these trends.

\section{Prévalence des anomalies oculaires congénitales dans une unité de soins pédiatriques au Ghana}

RÉSUMÉ Les données épidémiologiques sur les anomalies oculaires congénitales sont rares au Ghana. Nous avons étudié rétrospectivement les dossiers cliniques de 485 patients admis dans l'unité de soins oculaires pédiatriques du centre hospitalier universitaire de Korlé-Bu (Ghana) entre 2004 et 2009. Le diagnostic d'au moins une anomalie a été posé dans 263 cas. L'acuité visuelle a été évaluée quantitativement chez 209 patients et 130 étaient atteints d'une déficience visuelle ; 49 cas présentaient une cécité bilatérale et 64 une cécité unilatérale. Globalement, l'anomalie congénitale la plus fréquente était la cataracte $(n=44)$. Chez les nourrissons, la cataracte était le diagnostic le plus fréquent (28/121). Les enfants en bas âge étaient fréquemment touchés par le rétinoblastome (10/65). Le glaucome était l'anomalie la plus fréquente chez les enfants d'âge préscolaire (9/39) et scolaire (10/38). Nous avons conclu que des causes évitables de cécité chez l'enfant étaient à l'origine de la plupart des anomalies oculaires congénitales. L'intensification de la promotion de la santé dans la communauté et des soins oculaires préventifs, la détection précoce et l'allocation de ressources suffisantes pour un traitement efficace permettraient d'inverser ces tendances. 


\section{Introduction}

Congenital eye anomalies are an important cause of childhood blindness [1], and account for $\sim 60 \%$ of cases [2]. Understanding the prevalence and types of childhood blindness provides useful information for its prevention. However, in Ghana, as in many other developing countries, there is paucity of information on the epidemiology of congenital eye anomalies. Some studies have reported little more than disease frequency [3] or were carried out in schools for the blind $[4,5]$.

Worldwide, there is inter-regional variation in the spectrum of congenital eye anomalies. In the developing nations, congenital cataract and glaucoma are the most common and are often attributable to avoidable causes $[6,7]$. In contrast, in developed countries, anophthalmos, microphthalmos and coloboma (AMC) are the leading anomalies seen at birth and are mainly due to unavoidable causes [8].

To the best of our knowledge, there has been no study on the epidemiology of congenital eye anomalies in Ghana. The present retrospective study was conducted to determine the type and frequency of congenital eye anomalies and associated visual impairment among children seen at a paediatric clinic in Ghana.

\section{Methods}

A retrospective case series was carried out using the clinical records of all children seen at the paediatric eye centre, Korle-Bu Teaching Hospital (KBTH), Ghana, with a diagnosis of congenital eye anomaly, from July 1,2004 to December 31,2009 . Only patients whose hospital records were available in the hospital at the time of the study were included.

Ophthalmological evaluation of the children at the centre included visual acuity, slit lamp examination, and dilated fundus examination. The study was conducted with the approval of the University of Cape Coast, Ghana and KBTH.
Data were collected for demographic characteristics, clinical diagnosis, age at presentation of anomaly, and laterality, types and frequency of anomalies. To identify any potential differences based on age, the patients were divided into developmental age groups as follows: infants, $<1$ to 11 months $(n=121)$; toddlers, $1-3$ years $(n=65)$; preschool children, 3-6years $(n=39)$; and school children, $6-16$ years $(n=38)$.

Anatomical site and etiology were categorized using a coding system that incorporated taxonomy previously used in research on childhood blindness [9]. Visual impairment and blindness were classified using the International Classification of Disease, 10th Revision (ICD 10) [10] as visual acuity of $<6 / 18$ to $6 / 60$ in the better eye and visual acuity of $<3 / 60$ in the better eye, respectively. In some infants, visual acuity was determined by qualitative assessment.

Descriptive statistics were used to analyse the data and SPSS, version 16 , used to generate frequencies, proportions and percentages. Continuous numerical data are presented as means and standard deviations (SD) and categorical data as percentages.

\section{Results}

A total of 485 patients [265 (54.6\%) male and 220 (45.4\%) female] were seen at the centre over the 6-year review period. There were 263 (54\%) patients (153 male and 110 female; ratio: 1.4: 1) with at least one congenital eye anomaly, with a mean age of 2.8 years (age range: 1 month to 10 years). Cataract was the most frequent finding $(n=44 ; 16.8 \%)$; followed by glaucoma $(n=37 ; 14.1 \%)$, esotropia $(n=29 ; 11.1 \%)$ and retinoblastoma $(n=21 ; 8.0 \%)$. Retinopathy of prematurity (ROP) and AMC were less frequent. Most patients presented at age $>11$ months $(n=142 ; 54.0 \%)$ with 121 (46.0\%) in infancy. Table 1 presents the frequency of congenital anomalies in the paediatric population.
Each age category had a unique distribution of anomalies. In the infant group, congenital cataract was the most frequent finding $(28 / 121 ; 23.1 \%)$. In the toddlers, the most frequent anomalies were retinoblastoma and congenital esotropia (both $10 / 65 ; 15.4 \%)$. In the preschool children, the most frequent anomaly was glaucoma $(9 / 39 ; 23.1 \%)$. In the school children, glaucoma was also the most frequent anomaly $(10 / 38 ; 26.3 \%)$.

The visual acuity of 54 infants could not be classified and they were excluded from the analysis. A total of 130 (62\%) of 209 patients presented with some level of visual impairment (visual acuity $<6 / 18$ in better eye) (Figure 1). Forty-nine (23.4\%) and $64(30.6 \%)$ patients were bilaterally and unilaterally blind, respectively (visual acuity <3/60) (Figure 2).

As shown in Figure 3, the classification of congenital eye anomalies according to anatomical site revealed that the major locations were the lens $(n=$ $36 ; 20.5 \%)$, whole globe $(n=30 ; 17 \%)$ and retina $(n=23 ; 13 \%)$.

The main causes of congenital eye anomalies in 56 children were intrauterine $(n=12 ; 6.8 \%)$ and hereditary $(n=9$; $5.1 \%$ ) factors (Figure 4). The etiology of congenital eye anomalies in 149 (84.7\%) children could not be determined.

\section{Discussion}

Over a period of 6 years from July 1 , 2004 to December 31, 2009, congenital eye anomalies constituted $54 \%$ of the admissions to the paediatric eye centre at KBTH, Ghana. Our prevalence estimate of $54 \%$ for congenital anomalies was markedly higher than that found in other clinical studies $[6,7]$ and some population studies [9]. Our result is most likely an overestimation of events in the overall population, because the paediatric eye centre at KBTH is a tertiary facility that receives referrals from the whole country, and thus it encounters children with major congenital abnormalities. It is expected that children with minor defects would 


\begin{tabular}{lccccc}
\hline Table 1 Frequency of congenital anomalies in the paediatric population & & & \\
Congenital eye anomalies & $\begin{array}{c}\text { Infants } \\
(\boldsymbol{n}=\mathbf{1 2 1})\end{array}$ & $\begin{array}{c}\text { Toddlers } \\
(\boldsymbol{n}=\mathbf{6 5})\end{array}$ & $\begin{array}{c}\text { Pre-school } \\
\mathbf{c h i l d r e n} \\
(\boldsymbol{n}=39)\end{array}$ & $\begin{array}{c}\text { Schoolchildren } \\
(\boldsymbol{n}=\mathbf{3 8})\end{array}$ & $\begin{array}{c}\text { Total } \\
(\boldsymbol{n}=\mathbf{2 6 3 )}\end{array}$ \\
& No. (\%) & No. (\%) & No. (\%) & No. (\%) & No. (\%) \\
Cataract & $28(23.1)$ & $8(12.3)$ & $4(10.3)$ & $4(10.5)$ & $44(16.8)$ \\
Craniofacial dystosis & $2(1.7)$ & $2(3.1)$ & $1(2.6)$ & $1(2.6)$ & $6(2.3)$ \\
Megalocornea & $2(1.7)$ & $2(3.1)$ & $1(2.6)$ & $1(2.6)$ & $6(2.3)$ \\
Ptosis & $5(4.1)$ & $7(10.8)$ & $1(2.6)$ & $2(5.3)$ & $15(5.7)$ \\
Nystagmus & $4(3.3)$ & $4(6.2)$ & $0(0)$ & $2(5.3)$ & $10(3.8)$ \\
Retinoblastoma & $5(4.1)$ & $10(15.4)$ & $6(15.4)$ & $1(2.6)$ & $21(8.0)$ \\
Glaucoma & $12(9.9)$ & $6(9.2)$ & $9(23.1)$ & $10(26.3)$ & $37(14.1)$ \\
Eyelid capillary haemangioma & $4(3.3)$ & $1(1.5)$ & $1(2.6)$ & $1(2.6)$ & $7(2.7)$ \\
Esotropia & $10(8.3)$ & $10(15.4)$ & $6(15.4)$ & $3(7.9)$ & $29(11.1)$ \\
Peter's anomaly & $6(5.0)$ & $0(0)$ & $1(2.6)$ & $1(2.6)$ & $8(3.1)$ \\
Nasolacrimal duct obstruction & $6(3.5)$ & $0(0)$ & $0(0)$ & $0(0)$ & $6(2.3)$ \\
Dermoid cyst & $3(5.0)$ & $2(3.1)$ & $2(5.1)$ & $0(0)$ & $7(2.7)$ \\
Corneal opacity & $3(5.0)$ & $2(3.1)$ & $1(2.6)$ & $1(2.6)$ & $7(2.7)$ \\
Anophthalmos & $1(0.8)$ & $3(4.6)$ & $2(5.1)$ & $2(5.3)$ & $8(3.1)$ \\
Microphthalmos & $4(3.3)$ & $1(1.5)$ & $1(2.6)$ & $0(0)$ & $6(2.3)$ \\
Other & $26(21.5)$ & $7(10.8)$ & $3(7.7)$ & $9(23.7)$ & $45(17.2)$ \\
\hline
\end{tabular}

be managed at peripheral hospitals. It is therefore difficult to infer with any degree of accuracy the prevalence of congenital anomalies in the Ghanaian population as a whole. Nevertheless, our findings emphasize the importance of establishing adequate resources for prevention, early detection, treatment and rehabilitation of congenital eye anomalies.

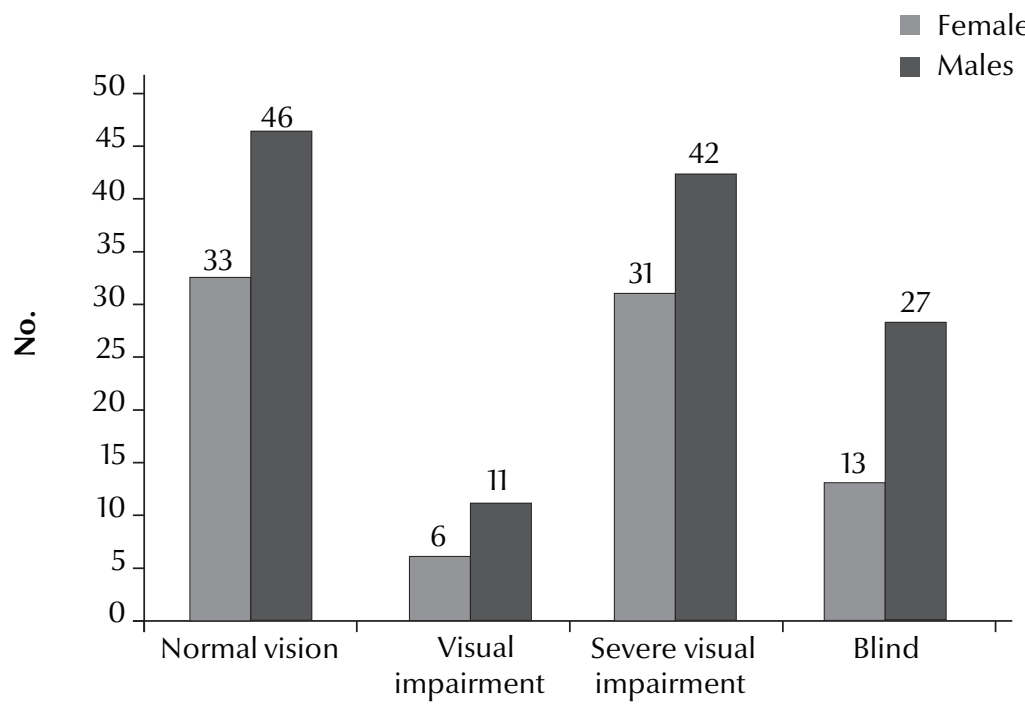

Figure 1 Visual acuity at presentation according to ICD 10
Congenital cataract and glaucoma were the leading clinical diagnoses and the major causes of blindness in our series. This corroborates findings from studies in schools for the blind in Ghana [3-5] and reports from Nigeria [6,7]. The frequency of visual impairment (62\%) in our study was comparable with that found in previous studies in

Females

Males 


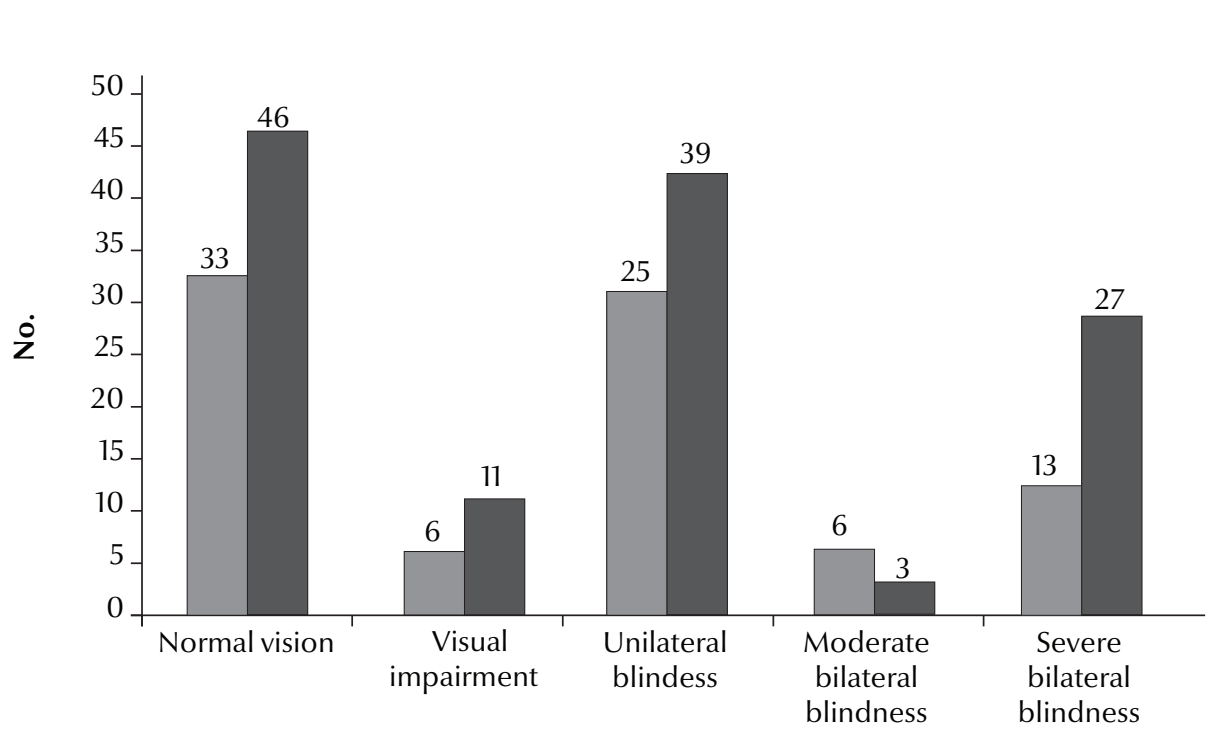

Figure 2 Prevalence of blindness using visual acuity at presentation

period [12]. In another study in Ilorin, Nigeria, 20 cases of retinoblastoma were diagnosed during an 11-year period [13]. Retinoblastoma is the second most common childhood malignancy in Ghana after lymphoma [14]. ROP was an extremely rare anomaly, with only two cases being seen over the 6-year study period. The low prevalence of ROP is in accordance with observations in other developing countries [6,7], thus confirming that the incidence of this condition has markedly declined in most developing countries as a result of improved

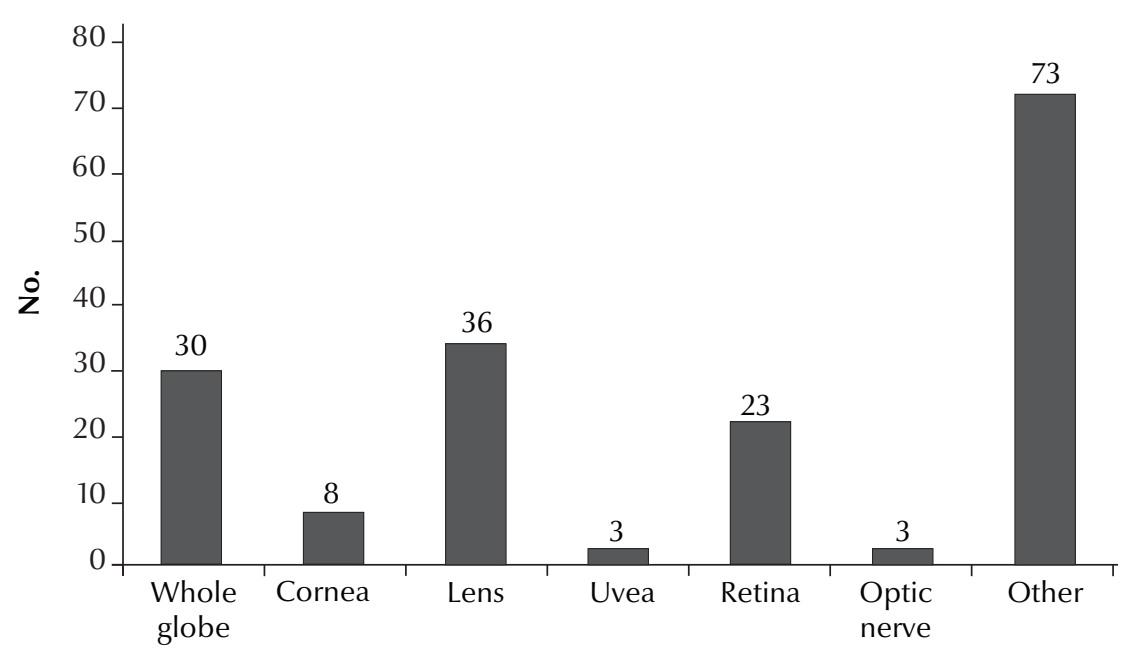

Figure 3 Major anatomical sites of congenital anomalies neonatal care. However, screening programmes to identify children at risk of ROP should be put in place.

We found that over half of the children first presented after infancy. The reasons for late presentation may include ignorance of the diseases and traditional beliefs [6]. For example, many people in rural areas believe that congenital eye problems are the result of witchcraft, which leads them to seek a spiritual cure. There is a need for further studies to establish why these children presented late in order to help
Females

Males

plan for effective and appropriate interventions to improve early detection and management and achieve better patient outcome. One notable finding of the present study was the unique distribution of anomalies in each age category, with congenital glaucoma being the most common anomaly among preschool and school age children and retinoblastoma among toddlers. In the resource-deficient setting in developing countries, this result has implications for prioritization of needs and resource allocation during future planning and implementation of intervention services for the paediatric population. The late presentation of patients with these conditions for medical care could result in poor prognosis for vision and sometimes for patient survival.

The etiological classification was based on the time of onset of the insult leading to visual loss, as reported by the parents in the clinical records. The etiology could not be determined from the clinical records in 149 (84.7\%) cases. However, intrauterine factors were found to be responsible for $12(6 \%)$ of the cases. Similar to our findings, Chuka-Okosa et al. [6] also reported that intrauterine factors were responsible for most of the cases. Hereditary factors were 


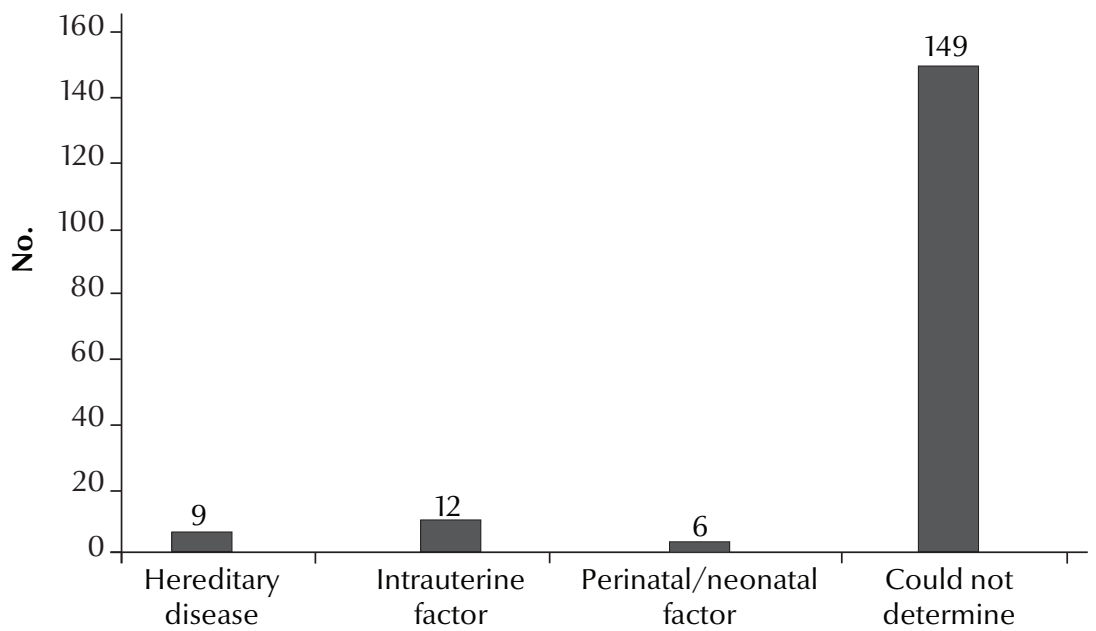

Figure 4 Causes of congenital anomalies

the second most common etiology in our study. There is a need to improve the etiological diagnosis of patients to facilitate effective prevention and health promotion. Establishment of specialized genetic clinics in tertiary centres in Ghana would help in this regard, together with community health education programmes to create awareness of the increased risk from consanguineous marriages, especially when there is a prevalence of a particular disease.

The demographic profile of our cases showed a slight predominance of infant and male patients, which corroborates the results of other studies [6,7]. However, the explanations are not immediately clear. It may be speculated that the national health care insurance scheme in Ghana may have led to an increase in the number of infant and male children utilizing clinical services.

There were some limitations to our study. It was retrospective in nature, hospital-based, and included a small number of patients, as a result of using only hospital records available at the time of study (some patients who see other specialists keep their own records). This makes it difficult to compare our results with those from other centres with larger series. Nevertheless, our findings provide some clues as to the pattern of congenital anomalies among children in Ghana.

In summary, the frequency of congenital eye anomalies was high in our study compared those in other developing countries. Most children were diagnosed with congenital cataract and glaucoma, which are avoidable causes of blindness, whereas a minority were diagnosed with ROP and AMC, which have been associated with childhood severe visual impairment and irreversible blindness. Our results suggest that congenital eye anomalies contribute significantly to childhood morbidity in Ghana. To reverse this trend, we recommend intensification of community-based health promotion and preventive eye care activities to ensure early detection, and provision of adequate resources for effective therapeutic intervention.

Funding: This research received no specific grant from any funding agency in the public, commercial or not-for-profit sectors.

Competing interests: None declared.

\section{References}

1. Levin AV. Congenital eye anomalies. Pediatric Clinics of North America, 2003, 50:55-76.

2. Gilbert C, Rahi JS, Quinn GE. Visual impairment and blindness in children. In: Johnson GJ et al., eds. The epidemiology of eye disease, 2nd ed.. London, Arnold Publishers, 2003:260-286.

3. Akafo SK, Hagan M. Causes of childhood blindness in Southern Ghana - a blind school Survey. Ghana Medical Journal, 1990, 24:113-119.

4. Ilechie AA, Otu-Danquah K. Causes of childhood blindness and severe visual impairment in schools for the blind in Ghana. Ghana Journal of Health, Physical Education, Recreation, Sports and Dance, 2010, 2:161-169.

5. Ntim-Amposah CT, Amoaku WMK. Causes of childhood visual impairment and unmet low-vision care in blind school students in Ghana. International Ophthalmology, 2008, 28:317323.

6. Chuka-Okosa CM, Magulike NO, Onyekonwu GC. Congenital eye anomalies in Enugu, South-Eastern Nigeria. West African Journal of Medicine, 2005, 24:112-124.

7. Lawan A. Congenital eye and adnexial anomalies in Kano, a five year review. Nigerian Journal of Medicine, 2008, 17:37-39.
8. Bermejo E, Martines- Frias ML. Congenital eye malformations: clinical-epidemiological analysis of 1,124,654 consecutive births in Spain. American Journal of Medical Genetics, 1998, 75:497-504

9. Gilbert $\mathrm{C}$ et al. Childhood blindness: a new form for recording causes of visual loss in children. Bulletin of the World Health Organization, 1993, 71:485-489.

10. International statistical classification of diseases and health related problems.Vols 1-3, 10th Revision. Geneva, World Health Organization, 1992.

11. Gogate P, Gilbert C. Blindness in children: a worldwide perspective. Community Eye Health, 2007, 20:32-33.

12. Essuman $\mathrm{V}$ et al. Presentation of retinoblastoma at a pediatric eye clinic in Ghana. Ghana Medical Journal, 2010, 44:10-15.

13. Owoeye JFA, Afolayan EAO, Popoola DSA. Retinoblastoma - a clinico-pathological study in Ilorin, Nigeria. African Journal of Health Sciences, 2006, 13:117-123.

14. Welbeck JE. Pattern of childhood malignancy in Ghana. West African Journal of Medicine, 1998, 17:81-84. 